\title{
添付型記憶媒体を用いた物体の位置姿勢推定
}

\section{Object-Pose Estimation using Multiple ID Devices}

\author{
○梅谷 智弘（名古屋市大） 正 井上 健司（大阪大） 正 新井 健生（大阪大） \\ *Tomohiro UMETANI, Nagoya City University, umetani@sda .nagoya-cu.ac.jp \\ Kenji INOUE, Tatsuo ARAI, Osaka University
}

\begin{abstract}
This paper describes a method for estimation of pose (position and orientation) of large objects such as construction materials using multiple ID devices attached to the objects. Object-pose tracking is crucial issue for integration of the objects and their information via ID devices since the workers or robots that do not have ID reader can change the object pose. The method uses the position and orientation of the ID reader with respect to the reference coordination frame. This paper focuses on the simplification of the estimation model to apply the method to the real environment. We discuss the feasibility of the method through the estimation model of the object-pose and numerical examples.
\end{abstract}

Key Words: Object pose estimation, ID device, radio frequency identification, construction site

\section{1. はじめに}

物体とその情報を関連づけるために，バーコードや RFID 夕 グなど添付型記憶媒体を用いる方法が, 情報の添付方法の容易さ やコストの面から注目され，様々な分野で適用されている。建設 作業では，搬入作業での通過管理 [1] や，作業現場における情報 管理 [2], 生産工場まで含めた物体追跡 [3] などの事例が存在す る. 物体と情報との統合手法の概念を図 1 に示す。添付型記憶媒 体を通して物体とその情報の操作が同時に行われ，物体を操作す るロボットや作業者と情報を操作する管理システムとが通信する ことで関連づけを行い，作業を達成する.

ところで，この情報の関連づけを利用するためには，物体と その情報との関連づけが正しく行われている必要がある. 関連づ けが正しくない場合, 物体に取り付けられた記憶媒体を介して 情報を取得する前提が成立しない。例えば，物体の位置姿勢は， 作業者やロボットが作業を達成するために重要な情報であるが, 物体は情報を更新できない作業者やロボットにより動かされる可 能性がある。一方，ロボットによる添付型記憶媒体からの情報取 得を利用した効率の良い動作生成手法の開発が望まれる。

本稿では, 物体に取り付けられた複数の添付型記憶媒体を利 用して建設資材など大きな物体の位置姿勢を推定する手法を考 察する [4]. 本手法では参照座標系における読み取り器の位置姿 勢が取得でき，そ扎ぞれの添付型記憶媒体について，物体座標系 における位置姿勢が登録されていることを仮定する。 Furlani ら は, 一直線上にない記憶媒体の読み取りにより, 読み取り器の位 置を利用して物体の位置姿勢を推定している $[5,6]$. また，梅谷 らは異なる向きの面に取り付けられた記憶媒体の読み取りにより 物体の位置姿勢を推定している [4]. 前者は， ロボットの動作を 前提としないため動作生成ができない問題が存在する，後者は， 記憶媒体の姿勢をすべて用いるため登録が困難であり，また，同 一面に添付された記憶媒体の読み取りによる位置姿勢が決まら ないため, 3 次元での位圆姿勢推定の実現が困難であった。

本報告では, 読み取り器における読み取り範囲を考慮した記 憶媒体と読み取り器の位置関係を求め, 物体に取り付けられた最 低 2 個の記憶媒体の読み取りにより物体の位置姿勢を推定でき ることを示す。本手法は記憶媒体の姿勢を方向べクトルで表現す ることで, 物体の生産時における座標の登録を容易にしている. 2 個以上の記憶媒体の読み取りにより物体の位置姿勢を推定す る際に, 読み取り器の姿勢について考察を行い, 物体の位置姿勢 推定に必要な情報を簡略化する，本手法の可能性を，モデルの考 察および数值例によって示す。

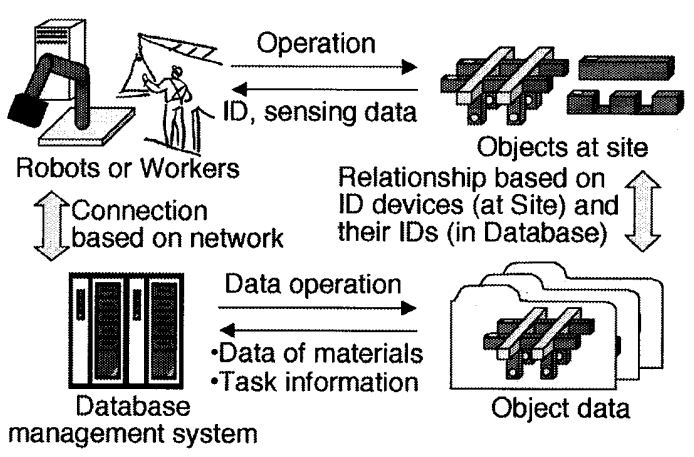

Fig.1 Integration of objects at the site and their information using ID devices.

\section{2. 添付型記憶媒体を用いた物体の位置姿勢推定}

\section{1. 添付型記憶媒体と読み取り器との関係}

最初に, 読み取り器として小型の RFID リーダを想定して読み 取り器による添付型記憶媒体の読み取りをモデル化する. RFID リーダは電磁波を出し, 通信範囲内に存在する IC タグに電力を 供給する。IC タグは反射波を出し, リーダは反射波から登録さ れた ID を取得する。.また, 記憶媒体が取り付けられた物体は読 み取り器の通信範囲より非常に大きいとする。 以上の条件を満足 する読み取り器の性質を以下にまとめる。

・読み取り器の正面軸方向近傍に読み取り範囲が存在する.

・読み取り範囲に記憶媒体が存在し, かつ, 読み取り器方向 を向く場合 ID 取得することができる．傾けることのでき る範囲は読み取り器に依存する。

・読み取り器は記憶媒体が正面軸範囲に回転しても ID を取得 できる。

これより, 読み取り器による添付型記憶媒体の読み取り時の モデルを検討する. 図 2 に, 添付型記憶媒体 $D_{1}$ と読み取り器の 位置関係を示す。図中の $\Sigma_{R, D_{1}}$ は読み取り器の座標系, $p_{c, D_{1}}=$ $\left[x_{c, D_{1}}, y_{c, D_{1}}, z_{c, D_{1}}\right]^{T}$ は. 読み取り器座標系における記憶媒体の位 置, $p_{D_{1}}$ は参照座標系における記憶媒体の位置, $R_{\Omega_{D_{1}}}$ は記憶媒 体の座標系における回転行列, $k_{D_{1}}$ は記憶媒体の向きを表す方向 ベクトルをそれぞれ示す. 方向ベクトル $k_{D_{1}}$ の大きさは 1 とす る. 実際には, $k_{D_{1}}$ は物体座標系における取り付け面の法線べク トルとして登録できる. 読み取り器の読み取り面は, 読み取り器 


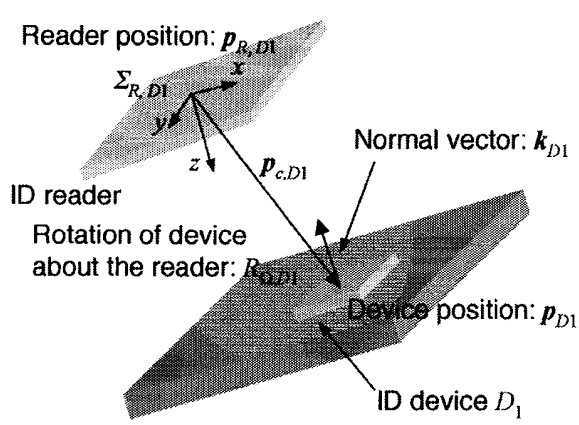

Fig.2 Model of ID reader and ID device.

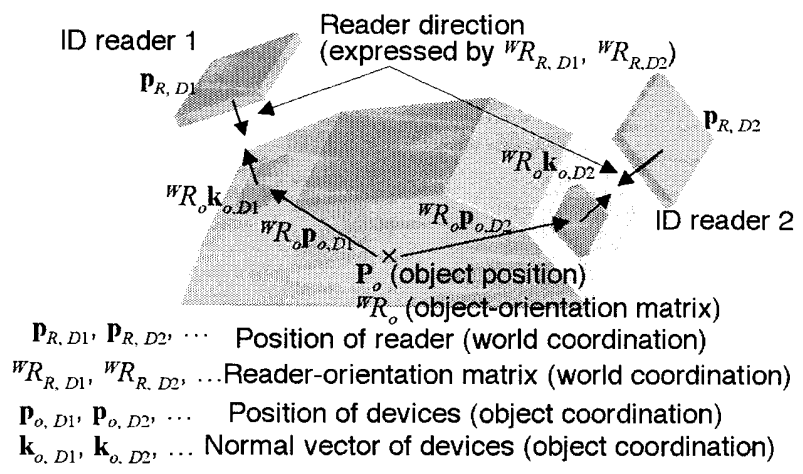

Fig.3 Pose estimation using two ID devices.

の座標系の $z$ 軸の方向に取るものとする。ここで, $x_{p, D}$, およ び， $R_{\Omega_{D_{1}}}$ の取りうる範囲は読み取り器に依存する，ただし，物 体の読み取り時には決定できないものとする。

また，記憶媒体は物体に取り付けられていることから， $p_{D_{1}}$ ， $k_{D_{1}}$ は, 物体の位置 $p_{o}$, 物体の姿勢行列 ${ }^{W} R_{o}$ は参照座標系にお ける物体の姿勢行列，および，物体座標系における記憶媒体の位 置 $p_{o, D_{1}}=\left[x_{o, D_{1}}, y_{o, D_{1}}, z_{c, D_{1}}\right]^{T}$, 物体座標系における記憶媒体の方 向ベクトル $k_{o, D_{1}}=\left[k_{x, D_{1}}, k_{y, D_{1}}, k_{z, D_{1}}\right]^{T}$ を用いて表現できる.

よって, 物体に添付された添付型記憶媒体 $D_{1}$ と読夕取り器と の位置や姿勢の関係は以下で表せる：

$$
\begin{aligned}
& p_{R, D_{1}}+{ }^{W} R_{R, D_{1}}\left[\begin{array}{l}
x_{c, D_{1}} \\
y_{c, D_{1}} \\
z_{c, D_{1}}
\end{array}\right]-{ }^{W} R_{o}\left[\begin{array}{l}
x_{o, D_{1}} \\
y_{o, D_{1}} \\
z_{o, D_{1}}
\end{array}\right]-p_{o}=0 \\
& { }^{W} R_{R, D_{1}}\left[\begin{array}{l}
0 \\
0 \\
1
\end{array}\right] \cdot{ }^{W} R_{o} R_{\Omega_{D_{1}}} k_{o, D_{1}}=-1 \\
& { }^{W} R_{R, D_{1}}\left[\begin{array}{l}
0 \\
0 \\
1
\end{array}\right] \times{ }^{W} R_{o} R_{\Omega_{D_{1}}} k_{o, D_{1}}=0 .
\end{aligned}
$$

記号 , ×はそれぞれ，ベクトルの内積，外積である。このとき， 物体の位置姿勢の取りうる範囲は, 読み取り器のパラメー夕に依 存した集合で表せる。読み取った各記憶媒体が読み取れる位置姿 勢に関する積集合が求める物体の位置姿勢の集合である。記憶媒 体 $D_{2}$ についても同様に表せる，よって，図 3 に示すように物体 の位置姿勢を複数の添付型記憶媒体を利用して推定できる。

\section{2. 物体の位置姿勢推定}

これより，最低 2 個の記憶媒体の相対位置関係から物体の位 置姿勢を推定するモデルを導出する，読み取り器による記憶媒体 の読み取りでは, 記憶媒体の読み取り器に対する傾きや読み取り
範囲内での位置は評価できない，そのため, 記憶媒体が読み取り 器が読み取った位置に存在し, その姿勢は読み取り器に対向して いると仮定して, 観測データによるモデルの推定問題として物体 の位置姿勢を推定する. したがって, 式 (1)の $x_{c, D_{1}}$ の項を微小 の誤差として扱い, 式(2)(3)における, 回転行列 $R_{\Omega_{D_{1}}}$ は単位行 列として扱う。

先に挙げた仮定を追加し, 読み取り器の位置姿勢の観測デー 夕による物体の位置姿勢の推定を行う。式 (1)(2)(3) は以下で書 き直せる。

$$
\left\{\begin{array}{l}
{ }^{W} R_{o} p_{o, D_{1}}+p_{o}=p_{R, D_{1}} \\
r_{D_{1}} \cdot{ }^{W} R_{o} k_{D_{1}}=-1 \\
r_{D_{1}} \times{ }^{W} R_{o} k_{D_{1}}=0 .
\end{array}\right.
$$

このとき, $r_{D_{1}}=\left[r_{x, D_{1}}, r_{y, D_{1}}, r_{z, D_{1}}\right]^{T}$ は記憶媒体 $D_{1}$ を読み取つた ときの読み取り器の方向ベクトルを表す．方向ベクトルの大きさ は 1 とする。ここで, 求めるものは物体の位置姿勢であるため, 物体の姿勢行列 ${ }^{W} R_{o}$ を,

$$
{ }^{W} R_{o}=\left[\begin{array}{lll}
n & s & a
\end{array}\right]=\left[\begin{array}{lll}
n_{x} & s_{x} & a_{x} \\
n_{y} & s_{y} & a_{y} \\
n_{z} & s_{z} & a_{z}
\end{array}\right]
$$

とおき, ベクトル $x^{T}=\left[p_{o}{ }^{T} n^{T} s^{T} a^{T}\right]^{T}$ とおくと, 記憶媒体 $D_{1}$ について式が7本成り立つ。ところで，式（4）からわかるよう に, 記憶媒体が同一線上に同じもしくは対向する向きで存在する 場合, 物体の位置に関する式が縮退する. 姿勢行列 ${ }^{W} R_{o}$ は回転 行列であることから, ベクトル $a$ を $n$ と $s$ の外積で表現する.

以上の手順により, 各記憶媒体についての観測データとして 表現することで, 物体の位置姿勢を推定できる.この場合, 読み 取り器の姿勢に関する式は同じ向きの場合, 読み取り器の誤差を 除くと同一になるが，位置に関する式は独立なので，最低 2 個の 記憶媒体の読み取りで, 9 個の変数に対して, 式が最低 10 本成 立する。したがって, 最低 2 個の記憶媒体の読み取りにより物体 の位置姿勢が推定できる。

\section{3. 数值例による検証}

提案手法の可能性を示すために，数值例によって提案したモ デルの妥当性を検討する、計算の正しさを検証するための読み 取り器による読み取り位置姿勢の誤差を含まない条件, および, 実際の条件に近い読み取り器による読み取り位置姿勢の誤差を 含んだ条件で検討する。

空間内の記憶媒体の配置は，記憶媒体を 2 個同一姿勢で離机 た位置に配置した条件（一直線上での配置条件）（条件 I ）。お よび，空間中に記憶媒体を 3 個一直線上にないように配置した 条件 (条件 2) を設定する。記憶媒体の配置条件は, 空間内に適 当に配置し，それぞれの記憶媒体の間隔は $1.0-2.0[\mathrm{~m}]$ とする. 条件 1 では, 方向ベクトルはもう 1 個記憶媒体を置いたと仮定し たときに作られる面に垂直な向きで同一にとる，すなわち，同一 面上に 2 個記憶媒体を配置した条件である，条件 2 では，方向べ クトルは 3 個の記憶媒体によって作られる面に垂直な向きで同一 にとる．すなわち，同一面上に配置されていることに相当する. これらを各記憶媒体の物体座標系における位置および方向べク トルとして記録し，参照座標系における変位を適当にとって空間 内に配置する。

読み取り器の配置は, 誤差を含まない条件では, 読み取り器 の位置は空間に配置された記憶媒体の位置，向きは，空間に配置 された記憶媒体の方向ベクトルの負の方向にとる. 誤差を含む条 件では, その条件に加えて, 位置変位を各軸で $\pm 20[\mathrm{~mm}]$, 回転 方向で方向ベクトルに垂直な向きに変位を $\pm 5.0, \pm 30.0[\mathrm{deg}]$ の 範囲内で適当に取る。変位の分布は一様分布とする。

以上の条件を設定して, Gauss - Newton 法により物体の位置 姿勢を求めた。初期解として, $\mathrm{p}_{o}=[0,0,0]^{T}, \mathrm{n}=[1,0,0]^{T}$, $\mathrm{s}=[0,1,0]^{T}$ を設定し物体の位置姿勢を計算した。誤差を含む条 件では, 各物体の配置ごとに 10 回読み取り器の配置を変更して それぞれで位置姿勢を求めた。条件 1 , 条件 2 のそれぞれで 10 
Table 1 Average estimation error of object pose.

\begin{tabular}{|c|c|c|}
\hline Conditions & $\begin{array}{c}\text { Average error of } \\
\text { position } \\
\text { (Min. - Max.) [mm] }\end{array}$ & $\begin{array}{c}\text { Average error of } \\
\text { angle for each axis } \\
\text { (Min. - Max.) [deg] }\end{array}$ \\
\hline $\begin{array}{c}\text { Condition } 1 \\
\text { (Reader err. } \pm 5[\mathrm{deg}])\end{array}$ & $32.70-74.06$ & $0.30-2.73$ \\
\hline $\begin{array}{c}\text { Condition } 2 \\
\text { (Reader err. } \pm 5[\mathrm{deg}] \text { ) }\end{array}$ & $29.90-64.76$ & $0.13-2.46$ \\
\hline $\begin{array}{c}\text { Condition } 1 \\
\text { (Reader err. } \pm 30[\mathrm{deg}])\end{array}$ & $62.00-406.50$ & $3.49-19.59$ \\
\hline $\begin{array}{c}\text { Condition } 2 \\
\text { (Reader err. } \pm 30[\mathrm{deg}])\end{array}$ & $27.55-64.86$ & $0.13-2.04$ \\
\hline
\end{tabular}

Table 2 Position error in the worst accurate case.

\begin{tabular}{|c|c|c|}
\hline Conditions & $\begin{array}{c}\text { Largest position } \\
\text { error [mm] }\end{array}$ & $\begin{array}{c}\text { Orientational error } \\
\text { for each axis [deg] } \\
\text { (Roll - Pitch - Yaw) }\end{array}$ \\
\hline $\begin{array}{c}\text { Condition 1 } \\
\text { (Reader err. } \pm 5[\mathrm{deg}] \text { ) }\end{array}$ & 153.47 & $2.66-1.84-6.60$ \\
\hline $\begin{array}{c}\text { Condition 2 } \\
\text { (Reader err. } \pm 5[\mathrm{deg}] \text { ) }\end{array}$ & 115.18 & $1.11-0.31-5.70$ \\
\hline $\begin{array}{c}\text { Condition 1 } \\
\text { (Reader err. } \pm 30[\mathrm{deg}] \text { ) }\end{array}$ & 937.28 & $9.56-2.00-34.20$ \\
\hline $\begin{array}{c}\text { Condition 2 } \\
\text { (Reader err. } \pm 30[\mathrm{deg}] \text { ) }\end{array}$ & 112.93 & $1.00-1.17-1.49$ \\
\hline
\end{tabular}

姿勢の位置姿勢を適当に与え評価した，誤差を含まない場合，い ずれの条件でも物体の位置姿勢は定まり，真値との誤差は各パラ メータ $10^{-12}$ 以下で収束した。

次に，位置および姿勢を読み取り時に変化した場合を想定し た条件についての結果を表 $1 ， 2$ に示す. 1 つの物体の位置姿勢 の推定についての表 1 は，物体の位置の誤差の大きさ，および, Roll-Pitch-Yaw 角の各軸に関する姿勢の誤差に関する平均の最小 值と最大值を示す。表 2 は, 物体の位置誤差が最も大きい推定結 果について, そのときの位置, 姿勢誤差である.これらの表は数 値実験結果であるため, 表の結果は, 数值そのものか議論の対象 ではなく，そ执ぞれの条件のもとでの，姿勢誤差の変化の度合い を定性的に示すものでしかないことに注意する.

表 1,2 に示すように, 条件 1 では, 読み取り器の姿勢誤差が 大きくなると物体の位置姿勢推定誤差は挔大する。一方，条件 2 では，一直線上にない記憶媒体の読み取りを行うことで，読み取 り器の姿勢誤差が大きい場合でも, 位置姿勢推定の誤差は, 一列 に並んだ記憶媒体の読み取りより小さくなることがわかる.

記憶媒体の向きが同一な一列に並んだ記憶媒体を読み取る場 合, 読み取り器の読み取り範囲, および許容される記憶媒体の傾 きの大きさのため, 物体の位置姿勢の誤差が大きくなる，読み取 り器の各範囲内に記憶媒体が存在すればその位置姿勢は, 物体の とりうる位置姿勢である。記憶媒体の向きが同一な一列に並んだ 記憶媒体を読み取る場合, 読み取り器に対する記憶媒体の傾きが 許容されるため，本手法では位置姿勢を精度良く推定することは 困難である。このとき，物体に取り付けられている記憶媒体によ り物体が識別されているので, 近くの記憶媒体の情報を知ること ができ，そして，位置姿勢は推定されているので，読み取り器に よる記憶媒体の探索が可能となる。また，そのときに，姿勢に関 する精探査を行い, 読み取り器の姿勢誤差を減少させておくこと が望まれる。このような動作計画を用いることで，物体の位置姿 勢を推定するためのロボットの動作生成が行える.

一方, 記憶媒体の向きが同一でない場合, 読み取り器の読み 取り範囲内に，記憶媒体が存在する条件があるため，物体の位置 姿勢推定精度は向上する。このことは，物体の位置姿勢推定が記 憶媒体の読み取りにより行えることを示唆している．また，位置 姿勢の推定に読み取り器の方向べクトルを利用するため，姿勢情 報が少なくてすみ，作業者の持つ読み取り器を利用した物体の位
置姿勢推定の可能性を示している.

ところで，位置姿勢推定手法によって得られた物体の位置姿 勢は，記憶媒体の読み取り範囲，および，許容される記憶媒体の 傾きの範囲内に存在するとは限らない.しかし，この推定結果を 初期値として, 記憶媒体が読み取り器の読み取り範囲に存在する 物体の位置姿勢を探索できる。

\section{4. おわりに}

本報告では, 読み取り器における読み取り範囲を考慮した記 憶媒体と読み取り器の位置関係を求め, 最低 2 個の記憶媒体の読 み取りにより物体の位置姿勢を推定できることを示した。数值例 を用いて本手法の可能性を検討した.

提案手法は物体座標系での記憶媒体の方向ベクトル，および， 読み取り器の方向ベクトルを利用するため, 記憶媒体の登録が容 易であり, 位置姿勢を推定するための読み取り器の条件が簡素化 されたため, 作業者による物体の位置姿勢推定が可能となった.

本手法を用いた位置姿勢推定実験の実施，より詳細な詔差の 解析, および，他センサ情報の利用による位置姿勢推定の精度向 上および簡単化はシステムの実用化に向けての課題である.

本研究は科学研究費若手研究 (17700189) のもとに行われた。

\section{文 献}

[1] E. J. Jaselskis, M. R. Anderson, C. T. Jahren, Y. Rodriguez and S. Njos, "Radio-Frequency Identification Applications in Construction Industry," Journal of Construction Engineering and Management, Vol. 121, No. 2, pp. $189-196,1995$.

[2] E. J. Jaselskis and T. El-Misalami, "Implementing Radio Frequency Identification in the Construction Process," Journal of Construction Engineering and Management, Vol. 129, No. 6, pp. 680-688, 2003.

[3] J. Yagi, E. Arai and T. Arai, "Parts and packets unification radio frequency identification application for construction," Automation in Construction, Vol. 14, No. 4, pp. 477 - 490, 2005.

[4] 梅谷智弘, 前泰志, 井上健司, 新井健生, 八木淳一, “複数の環境 添付型記憶媒体を用いた物体の位置姿勢推定”，日本ロボット学会 誌, Vol. 23, No. 1, pp. 84-94, 2005.

[5] K. M. Furlani and W. C. Stone, "Architecture for Discrete Construction Component Tracking," in Proceedings of the 16th IAARC/IFAC/IEEE International Symposium on Automation and Robotics in Construction, pp. $289-294,1999$.

[6] K. M. Furlani and L. E. Pfeffer, "Automated Tracking of Structural Steel Members at the Construction Site," in Proceedings of the 17th International Symposium on Automation and Robotics in Construction, pp. $1201-1206,2000$ 